\title{
NEOPLASIAS UTERINAS EM PATOS DE MINAS: dados epidemiológicos de 2013 a 2018 e a atuação do enfermeiro
}

DOI: 10.22289/2446-922X.V5N2A1

\author{
Laila Cristina de Freitas André Ribeiro ${ }^{1}$ \\ Elizaine Aparecida Guimarães Bicalho \\ Renata Ferreira dos Santos Oliveira \\ Marthius Campos Oliveira Santo
}

\section{RESUMO}

O presente estudo é uma análise sobre as neoplasias uterinas, seu conceito, índices de mortalidade, formas de prevenção e tratamento. O objetivo geral da pesquisa é analisar dados do DATASUS a respeito da incidência de câncer de colo de útero em residentes de Patos de Minas, no período de 2013 a 2017. Para alcançar o objetivo geral, traçaram-se os seguintes objetivos específicos: realizou-se um levantamento bibliográfico sobre o tema, com ênfase no papel do enfermeiro na prevenção e tratamento da doença. Em seguida, foram analisados e discutidos os dados do DATASUS. Este trabalho inscreve-se como uma narrativa conceitual, que se desdobrou em uma pesquisa bibliográfica. Como resultados, a pesquisa evidenciou uma taxa maior de mortalidade em mulheres de 70 a 75 anos e ainda relacionada esta taxa a baixa escolaridade das pacientes. O trabalho também discute sobre a frequência das internações e os anos com maior incidência de mortalidade

Palavras-chave: Câncer de colo de útero; Mortalidade; Cuidados de enfermagem.

\section{ABSTRACT}

Cervical cancer, because it is a serious public health problem, deserves attention and study. Research shows that early detection, through preventive tests, has more effective chances of cure. This leads to the assertion that the nurse's role, based on the family health program, improves health promotion. The strategy of harm reduction in daily care in the primary health care setting is required. This paper, in this line of reasoning, aimed to survey mortality rates; to specify the incidence of cervical cancer and discuss the data obtained from the perspective of the literature, trying to highlight the role of the nurse in this process. To reach this goal, methodologically, this paper is inscribed in a conceptual narrative, of a bibliographic nature based on statistical data found in DATASUS, in the epidemiological surveillance service of Patos de Minas - MG. As a result, the research showed a higher mortality rate in women aged 70 to 75

\footnotetext{
${ }^{1}$ Endereço eletrônico de contato: lailacristinaandre@hotmail.com

Recebido em 04/07/2019. Aprovado pelo conselho editorial para publicação em 29/10/2019.
} 
years and links this rate to low levels of education of those patients. The study also discusses the frequency of hospitalizations and the years with the highest incidence of mortality.

Keywords: Cervical cancer; Mortality rate; Nursing care.

\section{INTRODUÇÃO}

O câncer de colo de útero (CCU) é o terceiro carcinoma que mais atinge mulheres no Brasil, ficando atrás somente dos cânceres de pele não melanona e de mama. Ao se considerar somente as mulheres, esse tipo de neoplasia representa cerca de $15 \%$ de todos os tipos de câncer (Maia, Silveira, \& Carvalho, 2018).

Trata-se de um tema que se insere na esfera de saúde da mulher, ramo estratégico para medidas prioritárias do Sistema Único de Saúde (SUS), no nível de Atenção Primária. Muito embora, as medidas educativas e preventivas mostram-se insuficientes frente ao alto número de mortalidade registrado. O que se constata, outrossim, é que muitas mulheres quando realizam o diagnóstico já se encontram em estágios avançados da enfermidade (Soares, Mishima, Meincke, \& Simino, 2010).

O exame de Papanicolau detecta as alterações precoces que a neoplasia traz no organismo da mulher. O exame preventivo deve ser realizado em mulheres entre 25 a 64 anos de idade, que já tiveram início na relação sexual. Os dois primeiros exames devem ser realizados com intervalo de um ano, se os resultados forem normais, o exame passa a ser feito a cada três anos (Governo, 2018).

Um dos motivos que retardam o diagnóstico é que o CCU caracteriza-se por seu desenvolvimento lento. Tanto que na fase pré-clínica é assintomática, mas com modificações intraepiteliais progressivas importantes. A neoplasia pode se iniciar com pequenas lesões e progredir lentamente durante anos, figurando como sintomas iniciais, o sangramento vaginal, dor e corrimento (Costa, Weigert, Burci, \& Nascimento, 2017).

Segundo Barbosa, Souza, Bernal e Costa (2016), o papel do enfermeiro é fundamental desde a prevenção ao tratamento do CCU. Compete ao profissional da enfermagem a adoção de medidas que visem a prevenir, orientar e fomentar a realização do exame de Papanicolau. Também constitui um de seus deveres quebrar tabus com relação ao exame, tranquilizar a mulher no momento da consulta e empreender esforços para minimizar o desconforto durante 0 exame. Com isso, através de um trabalho proativo, o enfermeiro pode conseguir uma maior adesão de pacientes ao exame preventivo (Damacena, Luz, \& Mattos, 2017).

Diante disso, considerando o relevante papel do enfermeiro na prevenção e tratamento do CCU e, ainda considerando a alta incidência da patologia no Brasil, questiona-se:

Quais são as incidências de mulheres acometidas por câncer de colo de útero em Patos de Minas? 
Qual seria o perfil dessas mulheres?

Qual a incidência de internação de mulheres acometidas por neoplasias no útero, em Patos de Minas?

O objetivo geral deste trabalho é demonstrar, através de dados do DATASUS (Sistema de Informática do SUS), qual foi a incidência de mulheres acometidas por neoplasias no útero, em Patos de Minas, nos anos de 2013 a 2017.

Feito isso, foi necessário delinear os seguintes objetivos específicos: explanar sobre a incidência de câncer uterino no Brasil e no mundo, as formas de prevenção; descrever como é o papel do profissional da enfermagem na prevenção e tratamento do CCU e, por último, analisar e discutir os dados do DATASUS com o fim de demonstrar, quantitativamente, como é a incidência de neoplasia em mulheres de Patos de Minas, o perfil atingido, as frequências de internações, nos anos de 2013 a 2017.

Sendo assim, esta pesquisa representa especial relevância para o meio social, porque o câncer de colo uterino encontra-se entre as principais causas de mortalidade entre mulheres e esse fato induz ao questionamento sobre a real eficácia dos meios de prevenção e promoção à saúde da mulher.

A realização do trabalho justifica-se para o meio acadêmico, porque o enfermeiro hoje é considerado o profissional com melhor preparo para acompanhar mulheres, desde a prevenção até o tratamento do câncer de colo uterino. Portanto, é importante estudar com mais profundidade a teoria, as estatísticas e a importância da atenção da enfermagem e depois compará-la com resultados práticos e reais.

\section{MATERIAS E MÉTODOS}

Esta pesquisa inscreve-se como sendo uma narrativa conceitual, de cunho bibliográfico a partir de dados estatísticos encontrados no DATASUS, no serviço de vigilância epidemiológica do município de Patos de Minas - MG. A bibliografia consultada foi buscada em sites da internet como: Scielo, Buemi, BUS, usando como palavras-chave como câncer de colo uterino, mortalidade, cuidados de enfermagem. Foram selecionados artigos publicados em revistas eletrônicas, além de livros, teses, artigos e revistas da biblioteca da Faculdade Patos de Minas.

A pesquisa dividiu-se em três seções. A primeira, destinou-se a realizar um levantamento bibliográfico sobre a incidência de câncer do colo de útero, bem como sobre as formas de prevenção e tratamento. A segunda seção objetivou tratar sobre o papel do enfermeiro na prevenção e tratamento da enfermidade. A terceira seção dedicou-se a analisar dados do DATASUS sobre a incidência do CCU em residentes de Patos de Minas, nos anos de 2013 a 2017. 


\section{RESULTADOS}

O câncer de colo de útero (CCU) é considerado um grave problema de saúde pública e atinge mulheres em todo mundo. Cerca de $80 \%$ desses casos, são diagnosticados nos países em desenvolvimento, incluindo o Brasil (Soares et al., 2010). Conforme estimativas do Instituto Nacional do Câncer (INCA) a cada biênio, são diagnosticados cerca de 16.370 novos casos, com um risco aproximado de 15,43 casos a cada 100 mil mulheres (Governo, 2018).

No Brasil, a distribuição de novos casos, de acordo com a localização primária, é bem heterogênea entre os estados e capitais brasileiras. As taxas mais altas encontram-se nas regiões Sul e Sudeste com uma incidência de 28/100.000. Já na região do Norte e Nordeste as taxas são mais baixas, somando 22/ 100.000 e 17/100.000, respectivamente. No centro-oeste, a soma é intermediária, contando com 21/100.000 (Melo, Vilela, Salimena, \& Souza, 2012).

Com relação aos casos que levaram ao óbito, estudos comprovam que embora tenham diminuído nos últimos anos, o CCU ainda foi motivo de preocupação. Registre-se, que está alta taxa de mortalidade não se dá apenas em mulheres mais velhas, mas sua incidência ocorre nas mais variadas faixas etárias. O maior pico de incidência de CCU por porção ocorre em mulheres que contam entre 25 e 40 anos de idade. Já o carcinoma mais invasivo ocorre entre as que tem entre 48 e 55 anos (Soares et al., 2010).

Nas últimas décadas, os casos de CCU foram tão alarmantes que o problema tornou-se tema de saúde pública mundial. Muitos fatores explicam esta soma expressiva, dentre eles, podem-se ilustrar: pessoas desfavorecidas socioeconomicamente, idade, uso de contraceptivos, multiplicidade de parceiros, o não uso de preservativos e a preexistência de Doenças Sexualmente Transmissíveis (DST). Todos estes elementos, considerados isolada ou cumulativamente, são aptos a ensejar o câncer de colo uterino (Melo et al.,2012).

Um estudo realizado por Silva, Monteiro, Silva e Bicalho (2018) em Patos de Minas, a partir de dados do DATASUS, no período de 2013 a 2016, constatou, mais uma vez, a necessidade de realizar o exame Papanicolau com frequência. Conforme os dados levantados, foi possível observar que a chance de cura gira em torno 83,4\%. Destas ocorrências, constatouse que as internações variaram entre mulheres de faixa etária de 25 a 80 anos, sendo certo que o pico de maior incidência foi entre mulheres entre 35 a 39 anos, seguido das mulheres de 75 a 79 anos. Deste montante, 7 mulheres vieram a óbito, perfazendo um total de $18,42 \%$. Ainda assim, o estudo concluiu que a incidência de mortalidade por neoplasia, em Patos de Minas, é baixa.

Segundo Campos, Miranda, Britol, Aguiar e Celini (2016), câncer de colo de útero constitui o terceiro carcinoma mais recorrente em mulheres brasileiras. O início da doença pode se dar com uma lesão e progredir para algo mais invasivo em um período de 10 a 20 anos. 
Em que pese isso, o método tradicional para tratamento e cura da doença, ainda é o rastreamento, através do exame citopatológico do colo de útero ou teste de PCCU (Prevenção de Câncer de Colo de Útero), considerado de baixo custo, simples e de fácil execução (Damacena et al., 2017).

As altas chances de prevenção e cura elevam-se em razão do progresso lento da doença, caracterizado por fases bem definidas e facilidade em detectar precocemente os sintomas, o que viabiliza o diagnóstico, bem como o rápido e eficaz tratamento (Lima, Palmeira, \& Cipolotti, 2006). Para Brito-Silva, Falangola, Bezerra, Chaves e Tanaka (2014), o rastreamento precoce através do exame de Papanicolau, aliado ao tratamento da lesão intraepitelial, pode reduzir em 90,0\% a incidência deste tipo de câncer, refletindo expressivamente nas taxas de morbimortalidade. Todavia, o sucesso do tratamento depende também do estilo de vida do paciente e cobertura de rastreamento de, no mínimo, 80,0\% da população alvo (25 a 59 anos), segundo recomendação da Organização Mundial da Saúde (OMS).

Em países em que a citologia oncótica foi ampliada, de modo a conferir acesso à maior parte da população, evidenciou-se uma redução significativa nos casos de mortalidade. Não obstante isso, mesmo em países desenvolvidos, ainda existem mulheres que resistem em realizar o exame e algumas vão ao óbito em razão de falhas nos testes de Papanicolau (Mistura, Mistura, Silva, Melo, \& Sarmento, 2013).

Segundo Brito-Silva et al. (2014), no Brasil, houve uma melhora na cobertura do exame citológico. Mas ainda assim, ela é considerada insuficiente para o fim de mitigar a mortalidade por CCU. Para os autores, muitos fatores dificultam a cura e o tratamento. São eles:

O diagnóstico tardio dificulta o acesso aos serviços e revela, sobretudo, carência na quantidade e qualidade de serviços oncológicos fora das grandes capitais. Outros aspectos que podem contribuir para o diagnóstico tardio são: a baixa capacitação profissional na atenção oncológica, a incapacidade das unidades de saúde em absorver a demanda e as dificuldades dos gestores municipais e estaduais em definir e estabelecer um fluxo nos diversos níveis assistenciais (BritoSilva et al. 2014, p. 242).

A integralidade do Sistema Único de Saúde (SUS) implica em ofertar a todos da população, em seus diversos níveis, a assistência devida. Muito embora este direito tenha amparo constitucional, existem barreiras formais que impedem o acesso e continuidade de muitos pacientes ao tratamento. Estas barreiras existem tanto na atenção básica como nos serviços especializados (Costa et al., 2011).

Com o fim de enfrentar a doença efetivamente, o Programa Nacional de Controle do CCU no Brasil, dispõe que diferentes serviços públicos devem estar preparados para tratar cada etapa da doença. O rastreamento do CCU em mulheres que não apresentam sintomas é competência deste programa, sendo fundamental perquirir: a população-alvo, método e intervalo de 
rastreamento, metas de cobertura, infraestrutura nos três níveis assistenciais e garantia da qualidade das ações (Brito-Silva et al. 2014).

Conforme estudos de Navarro et al. (2015), em regiões nas quais existe alta prevalência de CCU, os programas de rastreamento são oportunistas, ou seja, não se dão de forma estruturada e organizada. Diante disso, os resultados não são plenamente confiáveis, de modo a dificultar também a elaboração de políticas públicas adequadas. Alguns dos erros comuns são a multiplicidade de exames em uma mesma pessoa e a negligência para com as mulheres mais carentes, que se beneficiaram mais com o exame de rastreamento.

O usuário de Sistema Único de Saúde (SUS), inicialmente, procura as Unidades de Atenção Primária à Saúde (UAPS), em que são acolhidos por enfermeiros, bem como por uma equipe multidisciplinar de Estratégia Saúde da Família (ESF). De acordo com a amplitude da área a ser atendida, as equipes são divididas com a missão de efetuar um trabalho integrado, com os residentes do local Instituto Nacional do Câncer [INCA] (2019).

Neste campo de atuação, os enfermeiros atuam desempenhando atividades técnicas específicas, em áreas administrativas ou pedagógicas. Deste modo, estabelecendo um elo com os usuários, os profissionais empreendem esforços no sentido de diminuir os tabus, estigmas e preconceitos, para atrair mulheres a fim de realizar a prevenção (Melo et al., 2012).

Com o fim de executarem as medidas e estratégias peculiares à demanda, é preciso considerar as particularidades de cada região, o que compreende: envolvimento de líderes comunitários, participação de agentes de saúde e movimentos de mulheres e mídia locais. E ainda assim, foi contatado que nos últimos anos a meta de cobertura não foi atingida, principalmente em se tratando de mulheres com idades entre 25 e 59 anos, consideradas de maior risco para o câncer do colo do útero (Soares et al., 2010).

Segundo Resolução oㅜ 381/2011, do COFEN (Conselho Federal de Enfermagem), a coleta de material para colpocitologia oncótica pelo método de Papanicolau é ato privativo de enfermeiro, observadas as devidas disposições legais. O enfermeiro deve ser capaz de realizar as habilidades inerentes à sua profissão, que assegurem rigor técnico-científico ao procedimento, sempre buscando atualizar-se e capacitar-se para exercer a profissão com primor (Resolução, 2011).

Oliveira, Silva, Araújo, Santos e Queiroz (2017) ressaltam que é competência do enfermeiro, por disposição do Ministério da Saúde, realizar condutas no sentido de prevenir o diagnóstico do CCU. No entanto, os autores ponderam que a realidade das unidades de saúde é complicada e existem múltiplos fatores que obstaculizam essas práticas. Como exemplo citase a dificuldade das pacientes em se dirigirem às unidades de saúde, pois muitas são responsáveis pelos afazeres do lar.

Nesta mesma linha de pensamento, Moreira (2016) afirma que realmente existe uma resistência em realizar o exame. Mesmo que a oferta seja gratuita, existem aspectos 
psicossociais que influenciam no momento de decidir realizar uma consulta. Neste panorama, cabe ao profissional de enfermagem ter a capacidade de compreender estas influências.

Campos et al. (2016) explica, de forma detalhada, que o enfermeiro deve ouvir e orientar a mulher antes da realização da coleta do material, a fim de acalmá-la durante a consulta. É preciso também coletar dados que assegurem a validade do exame, perquirindo se a mulher possui condições de realizar o exame e se cumpriu as orientações prévias. Um ponto a ser observado após a coleta do histórico da paciente, é constatar se a lâmina e o frasco que serão utilizados no exame, estão em perfeitas condições de higiene. O especulo deve ser introduzido com cuidado, sempre tentando diminuir o desconforto da mulher.

Sobre o papel do enfermeiro na prevenção do CCU, Linard, Silva e Silva (2002, p. 495) refletem:

Neste cenário os enfermeiros estão colaborando para o controle do câncer de colo uterino, à medida que proporcionam condições que possam contribuir para a cura ou minimizem as perdas funcionais e estéticas provocadas pela doença ou por seu tratamento. Além disso, o benefício social e econômico é bem maior, uma vez que, o custo do tratamento e as consequências da doença em fase avançada são elevados e ameaçadores (Linard et al., 2002, p. 495)

Conforme citado, o papel do enfermeiro assume especial relevância no exercício da prevenção e promoção da saúde. Portanto, uma das estratégias de redução de danos refere-se à detecção precoce, com a consequente melhora, na qualidade de vida do paciente. Entre as múltiplas atribuições do enfermeiro, encontram-se aquelas no sentido de formular e aplicar estratégias preventivas, sempre pautando-se nas orientações do Ministério da Saúde.

Para Oliveira et al. (2017), é essencial que os agentes comunitários de saúde (ACS) apoiem os enfermeiros, visando à melhor gestão das atividades que buscam a prevenção do CCU. Os ACS estão mais próximos da comunidade e, por isso, são conhecedores de suas realidades. Juntamente com os enfermeiros, os agentes podem realizar uma busca ativa de mulheres para realização de consultas. Uma forma interessante de captação é aproveitar quando os pacientes estão nas unidades de saúde para outros fins e sugerir a realização do exame (Santos, 2018).

Bezerra, Almeida e Therrien (2012) atentam para o fato de que muitas mulheres têm ciência de que é preciso realizar o exame de prevenção. No entanto, este conhecimento não é garantia de adesão e assiduidade em consultas ginecológicas.

Segundo Frigato e Hoga (2003) dizem que compete ao profissional da enfermagem dar amparo aos pacientes oncológicos durante o combate da doença, pois o câncer requer um tratamento longo e complicado. Este emaranhado de transformações nas relações sociais do pacientem reflete também em sua família, então, durante o tratamento, as mulheres ficam angustiadas e fragilizadas. Muitas mulheres buscam aprender tudo que podem a respeito da doença, as formas de tratamento e os efeitos da quimioterapia. 
A corroborar este entendimento, Oliveira et al. (2017, p. 196) ponderam que:

O saber do paciente deve ser valorizado pelo profissional de enfermagem, levando em consideração a diversidade sociocultural do mesmo. Dessa forma, uma relação horizontal entre profissional e paciente poderá ser estabelecida, facilitando na prática dialógica do profissional mediador da educação em saúde (Oliveira et al., 2017, p. 196).

Assim agindo, o profissional da enfermagem envolve-se ativamente no tratamento, participando, inclusive, das decisões. Compete ao enfermeiro dar orientações, informações, apontar os efeitos colaterais e atuar no sentido de minimizá-los. Para tanto, as ações do enfermeiro devem ser individualizadas, considerando as particularidades de cada paciente. É interessante, também, oferecer informações impressas, visto que é um recurso que abrange um maior número de pessoas e reforça as orientações realizadas na consulta (Santos, \& Souza, 2014).

\section{DISCUSSÃO}

Após detida leitura dos arquivos extraídos do Departamento de Informática do SUS (DATASUS), realizado pelo serviço de vigilância epidemiológica do município de Patos de Minas - MG, foi possível encontrar os seguintes resultados, consubstanciados nos gráficos abaixo.

Gráfico 1 - Mortalidade por cap. 02 (neoplasias de útero)

CID-10 em residentes no município de Patos de Minas, 2013-2018

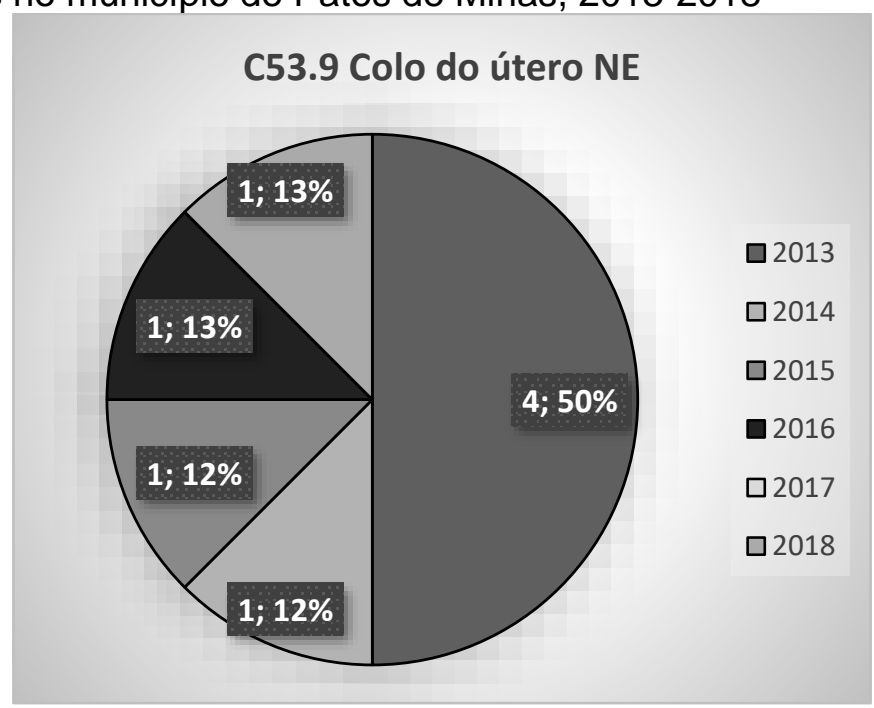

Fonte: (DATASUS, 2019)

Conforme exposto no gráfico 1, o ano de 2013 ostentou o maior de número de morte por neoplasias de útero, número bastante expressivo, considerando os anos seguintes, que tiveram estimativas que giraram em torno de 1,12 e $1,13 \%$. 
Considerando as estimativas em níveis mundiais, a mortalidade foi moderadamente baixa, tendo em vista que o número de letalidades foi menor que um terço da ocorrência. Registra-se, ainda, que teve alta prevalência em 2012 de sobreviventes, tendo este número alcançado o patamar de 8,7 milhões. A neoplasia maligna apresentou 266 mil mortes em 2012, o que corresponde a 7,5\% dos óbitos por câncer em mulheres no mundo (Governo, 2018).

Em Minas Gerais, os dados apontam que no biênio 2016/2017, houve uma estimativa de 9.63 novos casos de câncer de colo de útero, para cada grupo de 100 mil mulheres (Tavares e Moreira, 2017).

Gráfico 2 - Mortalidade por lesão invasiva do colo do útero em residentes no município de Patos de Minas, 2013-2018

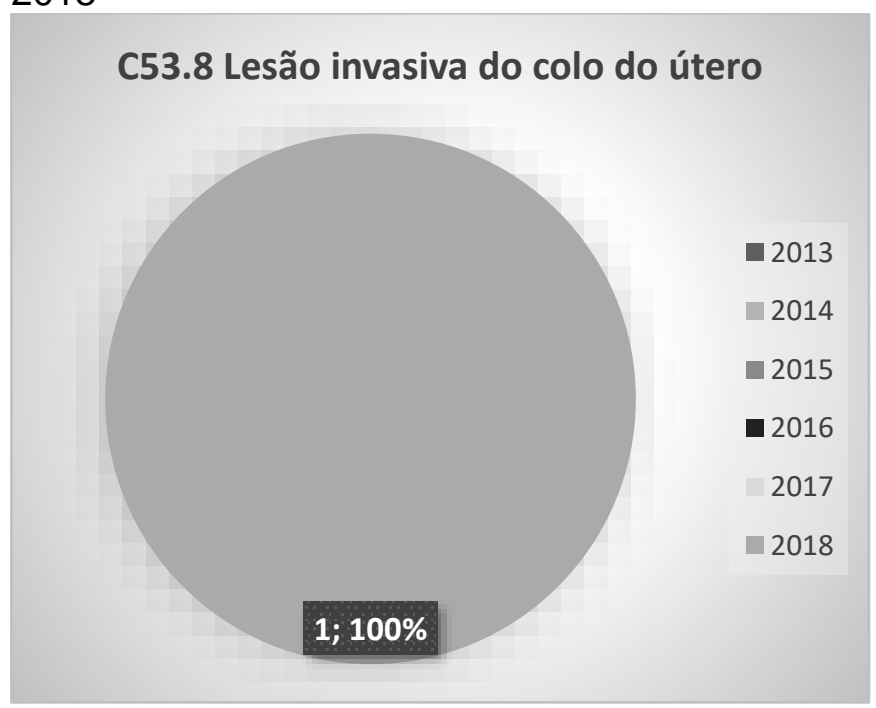

Fonte: (DATASUS, 2019)

De acordo com o gráfico 2, os arquivos demonstram que no ano de 2018 a incidência de mortalidade por lesão invasiva do colo do útero foi de $1 \%$.

Segundo Campos et al. (2016), o fator de preponderância para a ocorrência de lesões intraepiteliais de alto grau (precursoras do câncer de colo do útero) e do câncer de colo uterino é o contágio do vírus HPV. Segundo dados do Instituto Nacional do Câncer (INCA), existem mais de 200 tipos desta infecção, sistematizados em subtipos de baixo risco e de alto risco, para a evolução do carcinoma. Alguns dos tipos de alto risco, se combinados, desencadeiam aproximadamente $70 \%$ dos casos de carcinoma cervical (INCA, 2019).

É possível detectar o HPV congênito, através de testes de polimerase chain reaction $(\mathrm{PCR})$, em praticamente quase todos os casos de câncer de colo uterino. É possível ocorrer também em outros tipos de câncer, como: anal, cavidade oral, de pênis, vulval, vaginal e de faringe. O mais comum, contudo, é o câncer de células escamosas, responsáveis por 85 a $90 \%$ dos casos. Depois dele, vem o adenocarcinoma (Campos et al., 2016). 
Gráfico 3 - Mortalidade por câncer no endométrio em residentes no município de Patos de Minas, 2013-2018

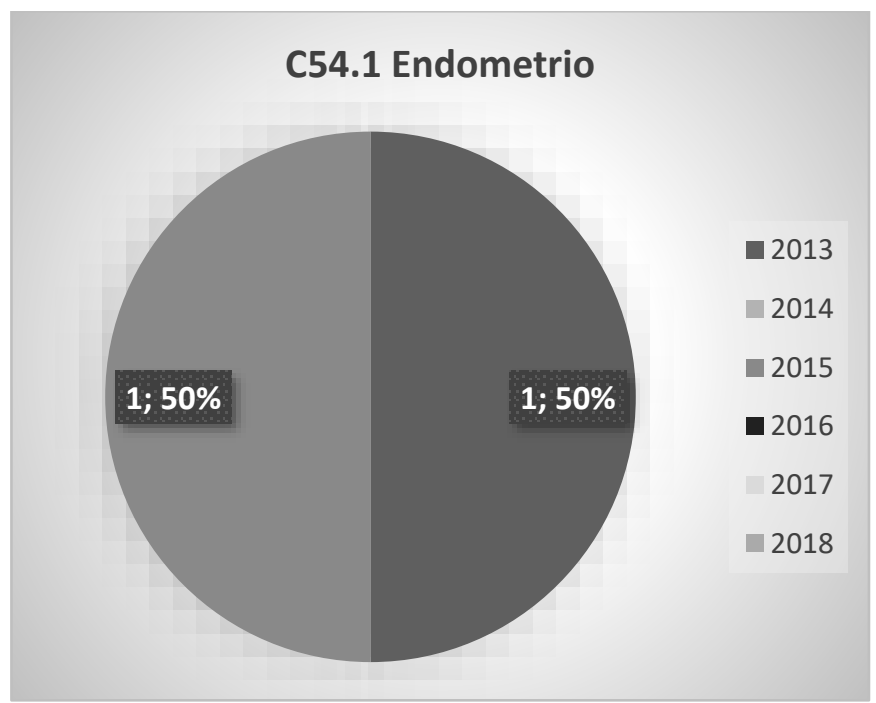

Fonte: (DATASUS, 2019)

O gráfico 3 demonstra que em 2013 e 2015 a incidência de mortalidade por câncer no endométrio em Patos de Minas, foi de 1,50\%.

Segundo dados do INCA, o carcinoma do endométrio é o sexto tipo de câncer mais comum entre mulheres, sendo relatados cerca de 6.950 casos em 2016 (INCA, 2019).

Um estudo realizado no Hospital de Clínica da Universidade Federal do Triângulo Mineiro, no período de dezembro de 2012 a junho de 2013, relatou que o perfil mais expressivo de paciente, foi de mulheres com câncer de mama, endométrio ou colo do útero, na faixa etária entre 51 e 60 anos. Estas pacientes residiam em Uberaba/MG, possuíam ensino fundamental incompleto e a maioria se ocupava dos afazeres da casa e possuíam renda de aproximadamente um salário (Silveira et al., 2016).

Gráfico 4 - Mortalidade por cap. 02 (neoplasias de útero porção) CID-10 em residentes no município de Patos de Minas, por faixa etária, 2013-2017

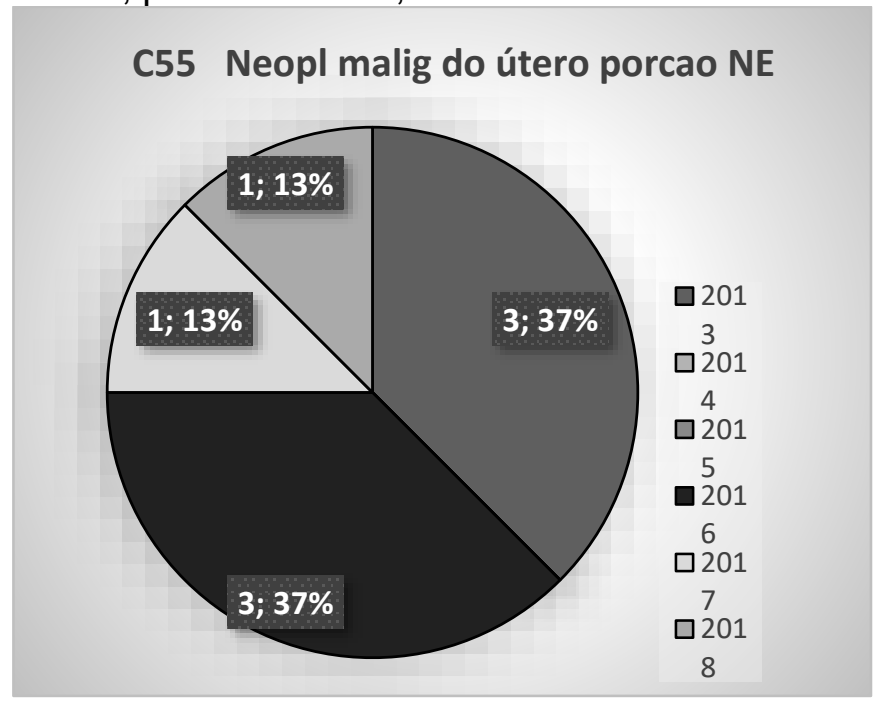


Fonte: (DATASUS, 2019)

O gráfico 4 demonstra uma maior incidência de mortes por neoplasias de útero porção nos anos de 2013 e 2016, alcançando um patamar de 3,37\%. Estes registros caem pela metade nos anos de 2017 e 2018, o que demonstra um avanço nas medidas de tratamento.

Um estudo realizado em 2012 com base nas informações constantes do Sistema de Informações sobre Mortalidade (SIM) demonstrou que, nos anos de 2004 a 2006, a taxa bruta de mortalidade foi de 3,6 óbitos por 100 mil mulheres em Minas Gerais (Teixeira, Valente, \& Franca, 2012). Os mesmos autores ainda complementam estas informações, afirmando que

[...] assim como na maior parte mundo, as taxas de incidência e mortalidade do CCU têm mostrado um declínio nos dados nacionais do Brasil, onde, nos últimos anos, as doenças crônicas não transmissíveis - DCNT - têm sido foco de políticas de prevenção, promoção da saúde, e de trabalhos intersetoriais integrados com a assistência médica (Teixeira et al., 2012, p. 01).

Não seria demais esclarecer, que as ações governamentais no sentido de incentivar a prática de exames e prevenção devem continuar a ser aprimoradas para o fim de diminuir as mortes por CCU, haja vista que as taxas de mortalidade por esta doença em países desenvolvidos são inferiores a 2 óbitos por 100 mil mulheres (Santos, \& Souza, 2014).

Gráfico 5 - Mortalidade por faixa etária (câncer de colo de útero) em residentes no município de Patos de Minas, por faixa etária, 2013-2017

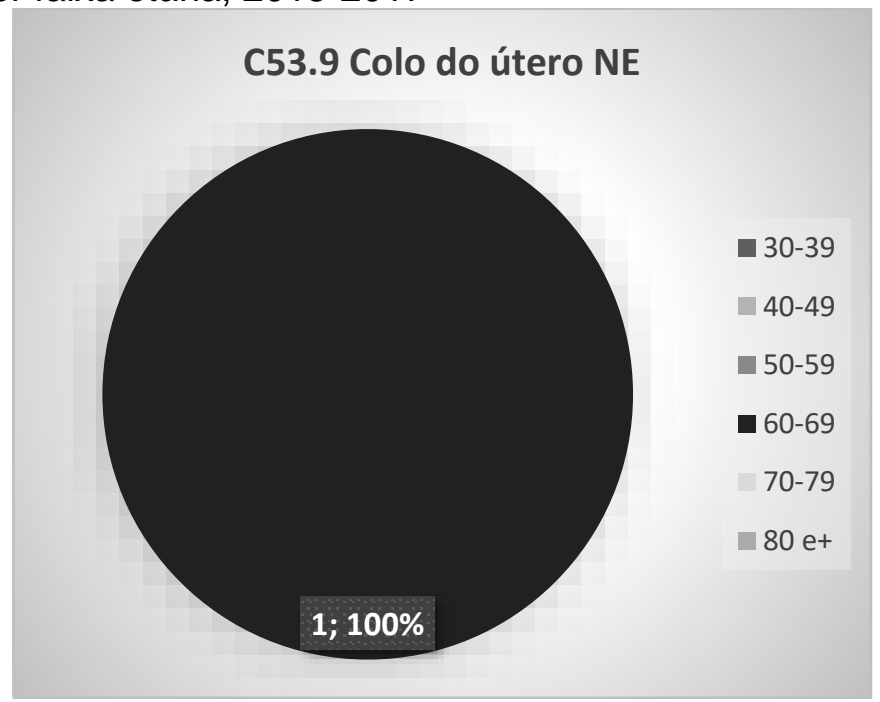

Fonte: (DATASUS, 2019)

O Gráfico 5 evidencia os índices de mortalidade que ocorreram em Patos de Minas, por câncer do colo de útero, considerando a faixa etária, no período de 2013 a 2018. Nota-se que as mortes deram-se eminentemente entre mulheres na faixa dos 60 a 69 anos.

Um estudo publicado na Revista Saúde e Desenvolvimento, em 2015, realizado a partir de realizado na Unidade Básica de Saúde Delson Pinheiro de Aguiar do Município de Serranópolis de Minas-MG, apontou que mulheres com faixa etária em torno de 40 e 60, Rev. Psicol Saúde e Debate. Dez., 2019:5(2):01-23. 
especialmente as negras, com pouca instrução, revelaram maiores dificuldades em realizar o exame, o que evidencia a menor eficiência das técnicas de incentivo do Estado para esta parte da população (Dias, Santos, Dias, Alves, \& Soares, 2015).

Vilaça, Martins Junior, Scherrer, \& Rodrigues (2012) realizaram um estudo com posterior publicação na Revista Brasileira de Cancerologia, no ano de 2012, através de dados do Programa Nacional de Controle do Câncer do Colo do Útero e de Mama - Viva Mulher, em que foi apontado que, em 2010, a incidência de realização de exames citopatológicos para rastreamento do câncer do colo do útero para a população feminina de 25 a 59 anos foi de 0,20\%. Por outro lado, para as pacientes com 60 anos ou mais, a incidência foi de $0,09 \%$. No município de Divinópolis, na Região Centro-Oeste de Minas Gerais, esta mesma taxa para as pacientes de 25 a 59 anos foi de $0,14 \%$ e para as pacientes com 60 anos ou mais foi de $0,09 \%$.

Nos Estados Unidos, a incidência do câncer do colo do útero é 50\% mais alta em afroamericanas se comparadas com as brancas. Em mulheres hispânicas, a incidência é $66 \%$ maior em detrimento das não hispânicas. Ao que se infere, as mulheres mais velhas, principalmente as que não são casadas ou convivem em união estável são mais acometidas por estágios mais severos da doença. Este número cresce quando se trata de mulheres afrodescendentes. Ademais, as mulheres com faixa etária de 60 anos ou mais, geralmente as viúvas, são surpreendidas com a doença em estágio avançado. Uma das principais razões é a não realização dos testes de rastreamento (Barbosa et al., 2016).

Gráfico 6- Mortalidade por faixa etária (Câncer no endométrio) em residentes no município de Patos de Minas, por faixa etária, 2013-2017

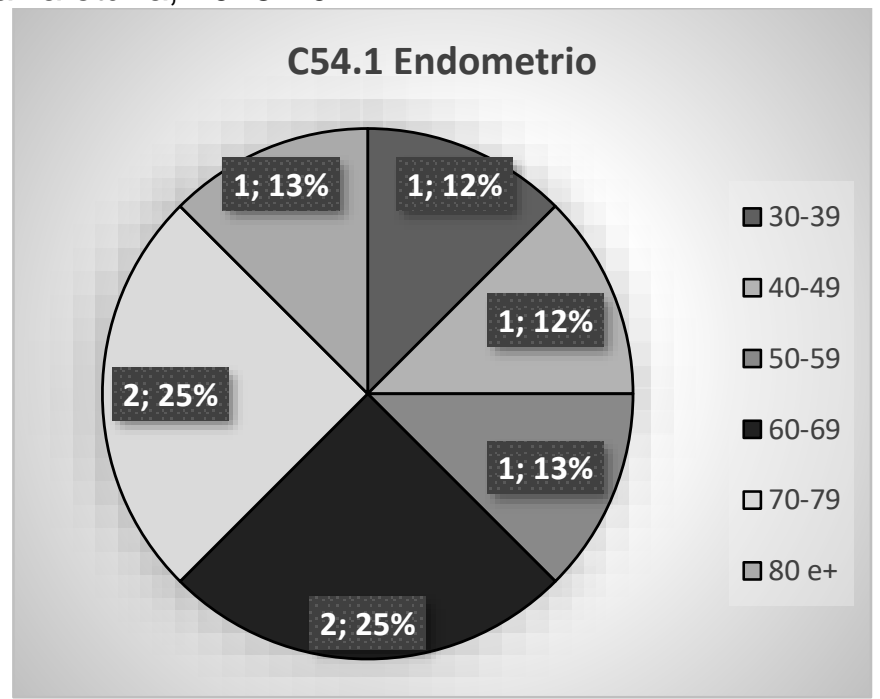

Fonte: (DATASUS, 2019)

O Gráfico 6 evidencia que a mortalidade em razão de câncer no endométrio em mulheres do município de Patos de Minas ocorre com mais preponderância em mulheres na faixa de 60 a 69 anos $(2,25 \%)$ e de 70 a 79 anos (2,25\%). 
No Brasil, e em outros países subdesenvolvidos, o câncer no endométrio é o responsável pela segunda causa de mortes por neoplasia maligna ginecológica, perdendo apenas para o câncer de colo uterino. De toda sorte, geralmente os diagnósticos são realizados no estágio inicial e a cura pode ser obtida por meio de intervenções cirúrgicas e tratamentos complementares. A taxa de sobrevida, em 5 anos, na neoplasia localizada é de $96 \%$, regional $67 \%$ e metastática 23\% (Ibiapina, 2012).

A literatura científica também reconhece o risco genético do câncer de endométrio. Isso porque cerca de $5 \%$ dos cânceres endometriais em mulheres de até 54 anos podem estar associados a história familiar (Ibiapina, 2012).

Para Costa e Cunha (2016) o câncer no endométrio em idosas resulta em mais riscos de morte, se comparados a pacientes jovens. No entanto, outras pesquisas sugerem que a idade não seja precisamente um fator de risco independente para recidivas (Bezerra et al., 2012).

Gráfico 7- Mortalidade por cap. 02 (neoplasias de útero) CID-10 em residentes no município de Patos de Minas, por escolaridade, 2013-2017

\section{C55 Neopl maligna do útero porcao}

NE

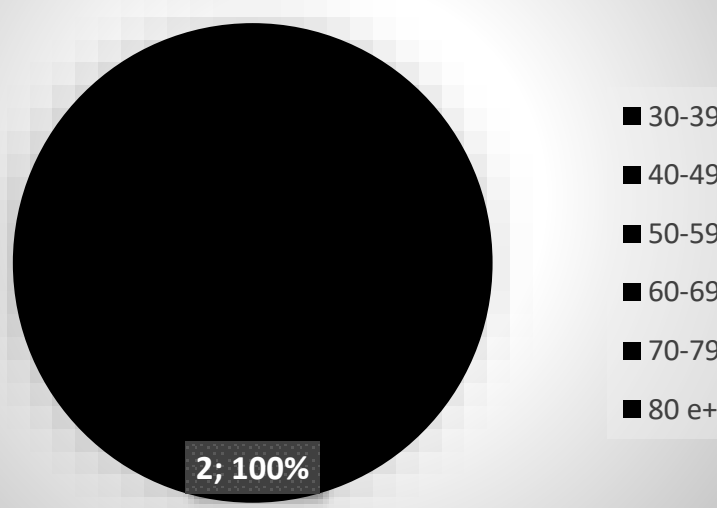

Fonte: (DATASUS, 2019)

O gráfico 7 revelou que a incidência de mortalidade por câncer de útero porção em mulheres com faixa etária de 70 a 79 anos é maior, considerando a baixa escolaridade destas mulheres. No tocante a este aspecto, em contraposição aos demais, ou seja, as outras faixas etárias, nota-se que a incidência é praticamente integral na faixa etária dos 70 a 79 anos.

Um estudo publicado pela Revista Brasileira de Cancerologia, promovido pelo INCA, em 2012, apontou que mulheres analfabetas ou mesmo as que têm ensino fundamental incompleto representam uma grande margem das que são acometidas pelo câncer de colo de útero. No referido estudo, elas representaram $70,9 \%$ da amostra. 0 estudo ainda demonstrou que a não realização do exame de Papanicolaou, com a consequente não realização do tratamento das lesões, relacionou-se à baixa ou alta idade, baixa escolaridade, baixo nível socioeconômico e 
cor parda. A incidência do câncer do colo do útero é mais frequente em mulheres de classes sociais mais baixas e com menor nível de escolaridade (Mascarello et al., 2012).

Os mesmos autores concluíram o seguinte, ao final do estudo:

Os resultados deste estudo mostram que a maior parte da amostra foi composta por mulheres de baixa escolaridade, fator de risco já conhecido para a doença quando relacionado à baixa condição socioeconômica. São necessários maiores investimentos em educação, pois isso será capaz de promover inclusão social e produzir resultados favoráveis nos indicadores de saúde mesmo que em médio e longo prazo. Deve-se ainda, ser assumido o compromisso de fornecer de forma equânime a assistência à saúde, principalmente aos mais distantes dos serviços de assistência (Mascarello et al., 2012, p. 424).

Gráfico 8 - Mortalidade por lesão invasiva do colo do útero considerando o tempo de escolaridade em residentes no município de Patos de Minas, por escolaridade, 2013-2017

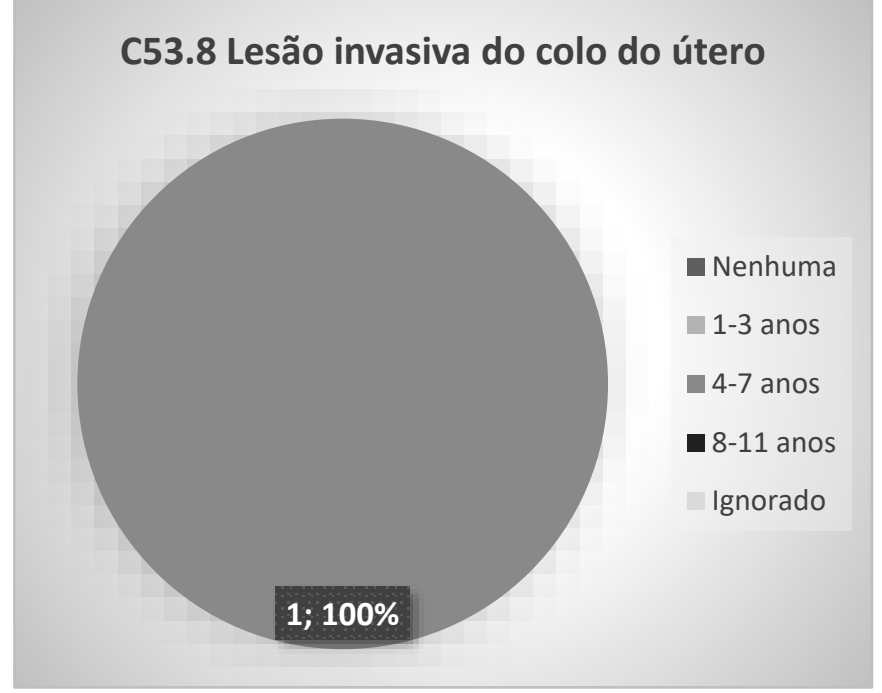

Fonte: (DATASUS, 2019)

Observe-se que o gráfico 8 revela que prevalece o número de mulheres acometidas com lesão invasiva do colo do útero com baixa escolaridade em Patos de Minas, no período de 2013 a 2018, sendo que a maioria frequentou a escola em um período de 4 a 7 anos.

Melo et al. (2012) realizaram um estudo sobre os fatores associados a alterações de exames citopalógico cérvico-uterino no sul do Brasil e concluíram que as mulheres acometidas por alterações nos exames, "a maioria era casada ou em união estável (72,8\%) e com baixa escolaridade (42,8\%), ou seja, menos de 8 anos de estudo. Quanto à etnia, prevaleceu mulheres de raça branca $(87,4 \%)$.".

$\mathrm{Na}$ fase de discussão do estudo, os autores corroboraram estes dados ao afirmarem que o nível de escolaridade figurou como um fator decisivo na decisão em realizar os exames. Estimou-se que 57,2\% das mulheres possuíam baixa escolaridade e, em razão disso, possuíam quatro vezes mais chances de serem acometidas por lesões de alto grau (Melo, Pelloso, Alvarenga, \& Carvalho, 2017). 
Oliveira, Guimarães e França (2014) também sustentam o mesmo entendimento de que mulheres com baixa escolaridade têm maiores dificuldades em realizar o ECCU. Este fator está associado ao sistema educacional que há décadas apresenta deficiências e acesso limitado para mulheres, que eram educadas somente para os afazeres do lar.

Gráfico 9 - Mortalidade por câncer de colo do útero considerando o tempo de escolaridade em residentes no município de Patos de Minas, por escolaridade, 2013-2017

\section{C53.9 Colo do útero NE}

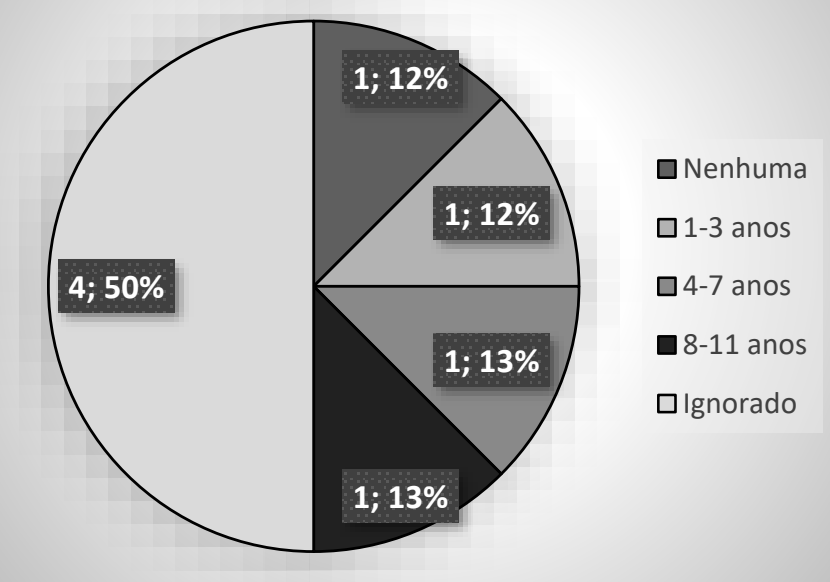

Fonte: (DATASUS, 2019)

O gráfico 9 revela que, em Patos de Minas, no período de 2013 a 2018, não foi declinado pelo DATASUS, o tempo de escolaridade de mulheres com maior taxa de mortalidade em razão de câncer por colo de útero. Este percentual ignorado alcançou uma cifra de 4,5\%. As com baixa escolaridade, ou seja, menos de 11 anos, apresentaram um percentual menor de mortalidade, ou seja, $1,13 \%$ e 1,12\% respectivamente. As que não foram acometidas pela neoplasia também somaram $1,12 \%$.

Um estudo publicado na Revista Caderno de Saúde Pública em 2016 sobre mães de filhos menores de 2 anos residentes no município de Juiz Fora/MG, demonstrou que a maioria das mulheres que nunca realizou o exame citopatológico do colo do útero era mais jovem $(55,5 \%)$, considerava-se não branca $(63,2 \%)$, era solteira $(65,9 \%)$, tinha menor escolaridade $(72,3 \%)$ e pertencia às classes sociais baixas $(87,2 \%)$ (Ribeiro et al., 2016).

Ribeiro et al. (2016), no desenvolvimento da pesquisa, questionaram as mulheres sobre a não realização do exame e obtiveram como resposta que o desconhecimento a respeito do exame, ou seja, sobre a sua finalidade e importância, figurou como um dos motivos principais. Também foi respondido que se sentiam saudáveis e imaginavam não ser necessário. Somente $5,7 \%$ das entrevistas responderam que tinha dificuldade em marcar a consulta, bem como realizar o exame. 
Desta forma, é comum em pesquisas a constatação de que baixa escolaridade e baixo nível socioeconômico são fatores cruciais para a não adesão ao exame citopatológico.

Gráfico 10 - Mortalidade por câncer no endométrio considerando o tempo de escolaridade em residentes no município de Patos de Minas, por escolaridade, 2013-2017

\section{C54.1 Endometrio}

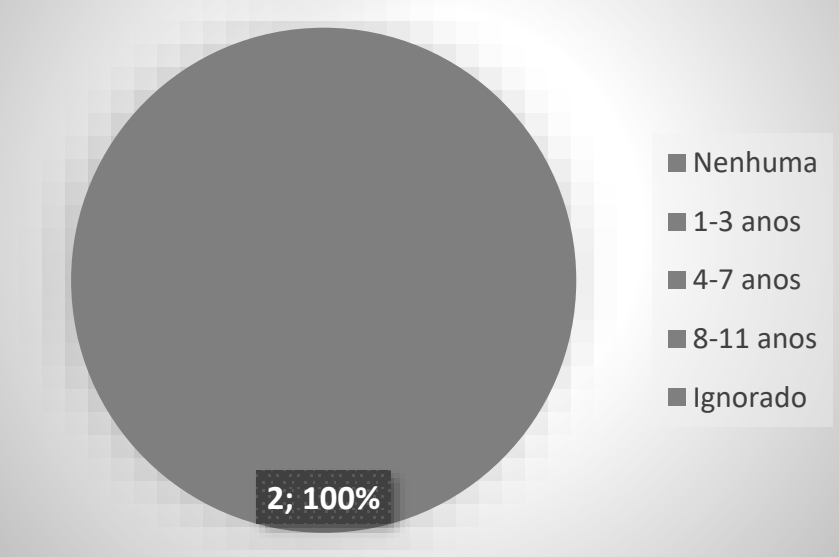

Fonte: (DATASUS, 2019)

O gráfico 10 também demonstrou que no período de 2013 a 2018, não foi declinado pelo DATASUS, o tempo de escolaridade de mulheres com maior taxa de mortalidade em razão de câncer endometrial.

O que se constata é que há uma escassez de dados neste sentido, ou seja, de delimitar qual o nível de escolaridade de mulheres acometidas por câncer no endométrio.

Faria e Fernandes (2017) realizaram uma pesquisa que foi publicada na Revista Interdisciplinar de Estudos Experimentais, em pacientes investigadas por sangramento pósmenopausa no Hospital Júlia Kubitschek e reconheceram-se que:

Em relação à escolaridade, houve dificuldade de avaliação devido à falta de informação nos prontuários - 69,7\% dos prontuários não possuíam essa informação. Pelos dados encontrados, $1,5 \%$ das pacientes era analfabeta; $18,2 \%$ possuíam ensino fundamental incompleto; $4,5 \%$, ensino fundamental completo; 4,5\% tinham ensino médio completo; e 1,5\% tinha ensino superior incompleto (Faria, \& Fernandes, 2017, p. 16).

Portanto, no estudo supracitado também houve a mesma constatação: a falta de informação quanto a escolaridade constante nos prontuários. Ainda assim, no referido estudo foi possível concluir que é preponderante o número de mulheres acometidas por câncer no endométrio, com baixa escolaridade. 
Gráfico 11 - Frequência de internações por neoplasias de útero em residentes no município de Patos de Minas, 2013-2017

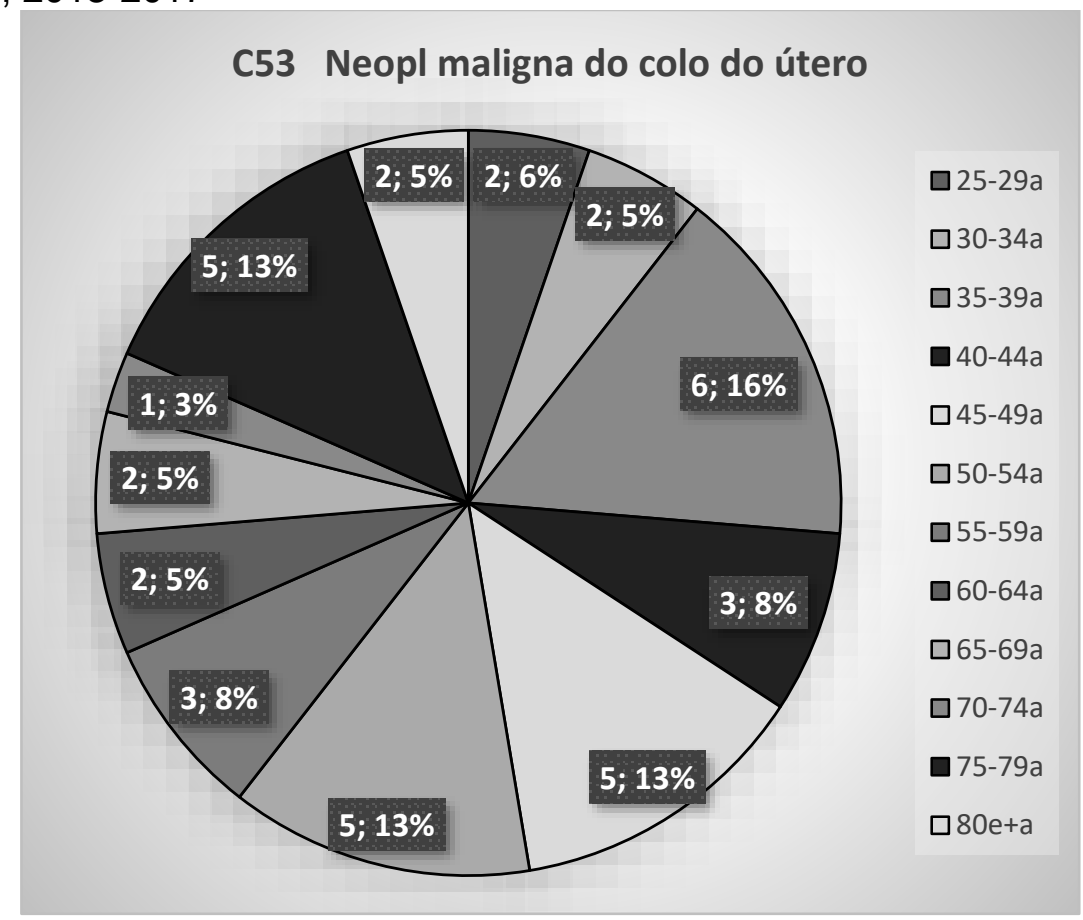

Fonte: (DATASUS, 2019)

De acordo com o gráfico 11, a frequência de internações por neoplasias do colo de útero no município de Patos de Minas, atingiu mulheres jovens a idosas, com mais de 25 a 79 anos.

Os índices mais expressivos de internações foram de mulheres com faixa etária entre 35 a 39 anos, o que somou $6,16 \%$, seguidas pelas de 45 a 49 anos, 50 a 54 e de 75 a 79 anos que alcançaram $5,13 \%$.

Santos, Moura, Santos, Figueria e Souza (2012) realizaram um estudo realizado no Serviço de Radioterapia do Instituto de Medicina Integral Prof. Fernando Figueira (IMIP), na cidade do Recife, com 34 pacientes com câncer do colo do útero que iriam iniciar tratamento com radioterapia adjuvante, exclusiva ou concomitante à quimioterapia, entre agosto e dezembro de 2011. Constatou-se que neste período

8 pacientes $(52,9 \%)$ foram internadas por complicações associadas ao câncer ou ao tratamento, em algum momento durante o estudo. As principais causas de internamento foram: sangramento transvaginal $(27,7 \%)$, dor $(22,3 \%)$ e trombose venosa profunda de membros inferiores $(16,7 \%)$. Não houve interrupção do tratamento em $64,7 \%$ dos casos. Nos casos de interrupção do tratamento, a principal causa referida foi anemia (66,7\%) (Santos et al., 2012, p. 509).

Segundo dados do INCA, com relação às características sociodemográficas, a faixa etária mais comum de incidência de câncer de colo de útero foi entre 50 e 60 anos. Predomina-se a 
presença de mulheres solteiras ou viúvas, o que sugere um prejuízo na qualidade de vida destas mulheres, visto que um parceiro poderia denotar uma certa segurança para a mulher, inclusive no que toca ao sustento da família. Ainda segundo dados do INCA, muitas mulheres contam com o amparo dos filhos e familiares, fato que pode ajudar no equilíbrio emocional, de modo a auxiliar no combate à doença e vontade de enfrentar o tratamento (Santos, 2018).

Gráfico 12 - Frequência de internações por neoplasias malignas do corpo do útero em residentes no município de Patos de Minas, 2013-2017

\section{C54 Neoplasia maligna do corpo do útero}

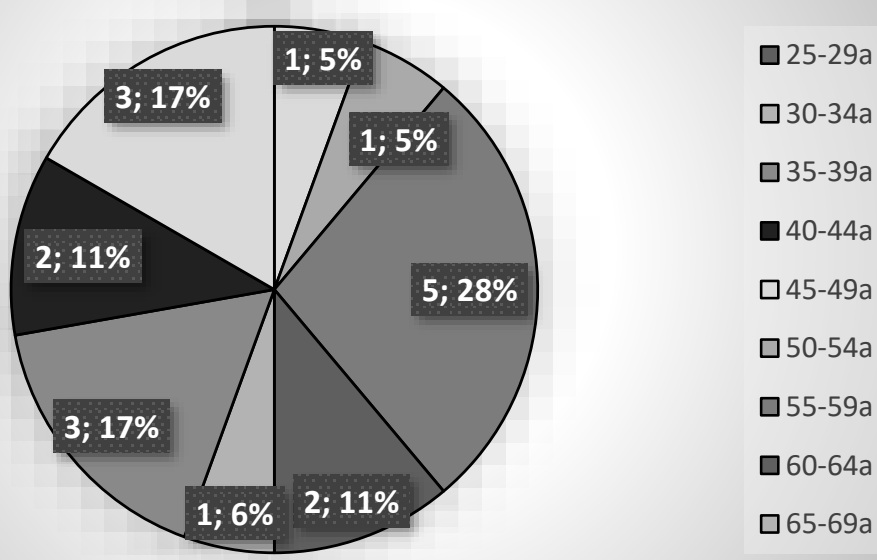

Fonte: (DATASUS, 2019)

Conforme evidenciado no gráfico 12, a frequência de internações de mulheres por neoplasias malignas no corpo do útero possui variações em praticamente todas as idades, depois dos 25 aos 74 anos. A maior incidência de internações ocorreu em mulheres de 55 a 59 anos, atingindo um percentual de 5,25\%, seguida pelas de 70 a 74 anos e 30 a 34 anos com um percentual de $3,17 \%$.

Uma pesquisa epidemiológica descritiva publicada em 2018, sobre internações de mulheres acometidas por câncer de colo de útero, no período de 2012 a 2016, em diferentes áreas demográficas, com base nos dados do DATASUS, constatou que no Brasil, no ano de 2012 teve 17521 internações, sendo certo que a raça branca foi a mais atingida, com 5733 internações. Destas internações, faixa etária mais atingida foi entre 40 a 49 anos (Feres et al., 2018).

Já em 2013, as internações reduziram para 16835, persistindo a raça branca como a mais afetada, desta feita, com mulheres em idade entre 40 a 49 anos. Em 2014 houve uma pequena diminuição no número de internações por câncer de colo de útero, somando 15343 casos, o que se observa também na faixa etária de 40 a 49 anos, 5709. No entanto, em 2014 a cor de maior incidência foi a parda (Feres et al., 2018). 
Segundo Feres et al. (2018), no ano de 2015, o número de internações continuou diminuindo, decaindo para 15338 casos. A faixa etária de 40 a 49 anos e a cor parda foram as mais acometidas. Em 2016, foram relatados 15341 casos, soma que aumentou sensivelmente com relação ao ano anterior. As cores que foram mais acometidas foram a parda e branca.

Gráfico 13 - Frequência de internações por neoplasias malignas do útero porção em residentes no município de Patos de Minas, 2013-2017

\section{C55 Neoplasia maligna do útero porcao NE}

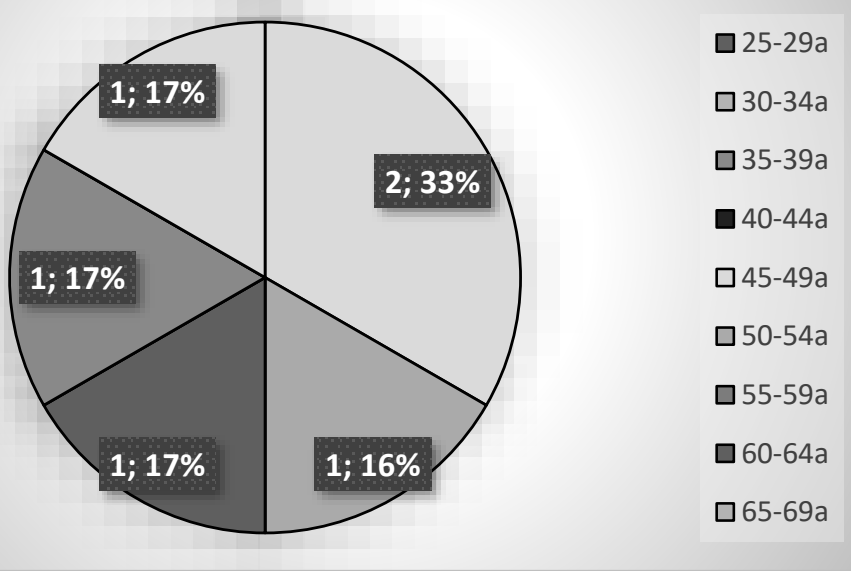

Fonte: (DATASUS, 2019)

O gráfico 13 trata da frequência de internações decorrentes de neoplasias malignas do útero porção, em mulheres de Patos de Minas. Analisando o gráfico, constata-se que a maior taxa de internação refere-se às mulheres com faixa etária de 45 a 49 anos. As demais apresentam níveis praticamente iguais, com uma sensível diferença de $1 \%$.

Uma pesquisa realizada em Piracicaba e publicada no Boletim do Instituto de Saúde em 2017, com base em dados do SUS e em entrevistas, apontou que no período de março a dezembro de 2006 houve 107,39 internações por 100.000 mulheres de 25 a 59 anos. Não se tem informação sobre o procedimento executado nas internações que pode ter sido cirurgia, ou as primeiras sessões de quimioterapia e/ou radioterapia, ou mesmo internação terminal para terapia paliativa.

Moreira (2016) afirma que o câncer de colo de útero é motivo de preocupação de países em desenvolvimento há décadas. Isso porque acomete mulheres em idade produtiva e de nível socioeconômico desprivilegiado. Quando estas mulheres adoecem, ocupam leitos hospitalares por tempo indeterminado e ficam afastadas de suas atividades laborativas. Do mesmo modo, necessitam ficam privadas do convívio familiar, de modo a ocasionar um expressivo prejuízo socioeconômico. Frisa-se que a internação pode ser evitada com a simples realização do exame Papanicolau. 


\section{CONSIDERAÇÕES FINAIS}

O câncer de colo de útero é considerado problema de saúde pública em razão das altas taxas de mortabilidade, mesmo diante das grandes chances de cura e recuperação quando a doença é diagnosticada no estágio inicial. A melhor forma de combate, no entanto, ainda continua sendo a prevenção. O CCU é capaz de provocar profundas alterações na vida de mulheres que sofrem desta enfermidade, pois grande parte delas estão em sua idade reprodutiva.

O presente estudo constatou que no ano de 2013 houve maior incidência de câncer em mulheres residentes em Patos de Minas, número bastante significativo considerando os anos seguintes. No ano de 2013, foi possível verificar-se também que as maiores vítimas foram mulheres na faixa dos 60 aos 69 anos.

Os autores estudados foram unânimes em afirmar que a maior taxa de incidência de câncer de útero dá-se em mulheres idosas e com baixa escolaridade. Isso pela vergonha em realizar o exame preventivo, pela desinformação e por acharem que estão saudáveis.

A frequência de internações também é maior em mulheres com mais de 35 anos e o que chama atenção é a falta de registro quando ao nível de escolaridade destas mulheres. Entretanto, outros estudos no país sugerem que mulheres com baixa escolaridade internam-se com mais frequência.

Com efeito, é necessário considerar as particularidades da população estudada, que geram um impacto positivo ou negativo nestes números. O estilo de vida destas mulheres, assim como a viabilidade de acesso aos serviços públicos, demonstra que motivo é a não realização de exames preventivos ou a demora em iniciar o tratamento.

De mais a mais, o conhecimento da epidemiologia deste agravo e sua relevância e magnitude social, torna-se fundamental para combater a enfermidade, pois ajuda o Poder Público a aplicar políticas e diretrizes especificas para cada local, bem como cada grupo de mulheres.

\section{REFERÊNCIAS}

Barbosa, I. R., Souza, D. L. B., Bernal, M. M., \& Costa, I. C. C. (2016, jan.). Desigualdades regionais na mortalidade por câncer de colo de útero no Brasil: tendências e projeções até o ano 2030. Ciência \& Saúde Coletiva, 21(1), 253-262. http://dx.doi.org/10.1590/141381232015211.03662015.

Bezerra, F. C., Almeida, I. M., \& Therrien S. M. N. (2012). Estudos sobre Envelhecimento no Brasil: Revisão Bibliográfica. Revista Brasileira de Geriatria e Gerontologia, 15(1), 155-167. Recuperado em 16 abril, 2019, de https://www.redalyc.org/articulo.oa?id=403838795017.

Brito-Silva, K., Falangola, A., Bezerra, B., Chaves, L. D. P., \& Tanaka, O. Y. (2014, abr.). Integralidade no cuidado ao câncer do colo do útero: avaliação do acesso. Revista de Saúde Pública, 48(2), 240-248. http://dx.doi.org/10.1590/s0034-8910.2014048004852. 
Campos, R. R., Miranda, M. M. S., Britol, H. M., Aguiar, R. A. L. P., \& Celini, M. (2016) Câncer de colo uterino: a doença como forma de violência. Recuperado em 12 abril, 2019, de http://rmmg.org/artigo/detalhes/2191.

Costa, J. H. G., Souza, I. R. A., Santos, J. A., Prezeres, B. A. P., Andrade. M. L., Melo, M. F. C., Tsutsumi, M. Y., \& Sousa, M. S. (2011, dez.). Prevenção do câncer de colo do útero em comunidades ribeirinhas atendidas pelo Programa Luz na Amazônia, Estado do Pará, Brasil. Revista Pan-Amazônica de Saúde, 2(4), 17-22. Recuperado em 15 maio, 2019, de http://scielo.iec.gov.br/scielo.php?script=sci_arttext\&pid=S2176$62232011000400003 \&$ lng $=p t \& n r m=i s o>$.

Costa, C., \& Cunha, T. M. (2016). Estadiamento do carcinoma do endométrio - O que há de novo? Acta Radiológica Portuguesa, 28(107), 13-20.

Costa, F. K. M., Weigert, S. P., Burci, L., \& Nascimento, K. F. (2017, nov.). Os desafios do enfermeiro perante a prevenção do câncer do colo do útero. Revista Gestão \& Saúde, 1(1), 55-62. Recuperado em 22 abril, 2019, de http://www.herrero.com.br/files/revista/filef125a619c4b18a99efe6fdf22874fdd6.pdf.

Damacena, A. M., Luz, L. L., \& Mattos, I. E. (2017, mar.). Rastreamento do câncer do colo do útero em Teresina, Piauí: estudo avaliativo dos dados do Sistema de Informação do Câncer do Colo do Útero, 2006-2013. Epidemiologia e Serviço de Saúde, 26(1), 71-80. Recuperado em 23 abril, 2019, de http://www.scielo.br/scielo.php?script=sci_arttext\&pid=S2237$96222017000100071 \& \operatorname{lng}=$ en\& $\mathrm{nrm}=$ iso

Dias, E. G., Santos, D. D. C., Dias, E. N. F., Alves, J. C. S., \& Soares, L. R. (2016). Perfil socioeconômico e prática do exame de prevenção do câncer do colo do útero de mulheres de uma unidade de saúde. Revista Saúde e Desenvolvimento, 7(4), 135-146.

Feres, T. M., Rodrigues, S. L., Coser, E. X., Ferreira, G. J., Merghmurer, L. A., Campos, T. G., \& Rocha, L. L. V. (2018, mar.). Prevalência de câncer no colo uterino: um estudo descritivo. Brazilian Journal Of Surgery And Clinical Research, 22(2), 54-58. Recuperado em 14 abril, 2019, de https://www.mastereditora.com.br/periodico/20180405_100803.pdf.

Frigato, S., \& HOGA, L. A. K. (2003, jul.). Assistência à mulher com câncer de colo uterino: o papel da enfermagem. Revista Brasileira de Cancerologia, 48(4), 209-214. Recuperado em 15 maior, 2019, de http://www1.inca.gov.br/rbc/n_49/v04/pdf/ARTIG01.pdf.

Governo do Estado do Paraná. (2018). Cenário epidemiológico da neoplasia maligna da mama e do colo do útero em mulheres residentes no Paraná. Paraná. CEPI. Recuperado em 12 abril, 2019,

de

http://www.saude.pr.gov.br/arquivos/File/Cenariodepidemiologcandecerdemama.pdf.

Ibiapina, J. O. (2012). Câncer do Corpo Uterino. In: S. C. Vieira et al. (Org.). Oncologia Básica. (pp. 137-149). Teresinha: Fundação Dom Quixote.

Instituto Nacional do Câncer. (2018). Câncer do Colo de Útero. Brasília. INCA. Recuperado em 12 abril, 2019, de https://www.inca.gov.br/tipos-de-cancer/cancer-do-colo-do-utero.

Lima, C. A., Palmeira, J. A. V., \& Cipolotti, R. (2006, out.). Fatores associados ao câncer do colo uterino em Propriá, Sergipe, Brasil. Cadernos de Saúde Pública, 22(10), 2151-2156. Recuperado em 15 maio, 2019, de http://www.scielo.br/scielo.php?script=sci_arttext\&pid=S0102311 X2006001000021\&lng=en\&nrm=iso

Maia, R. C. B., Silveira, B. L., \& Carvalho, M. F. A. (2018, abr.). Câncer do colo do útero: papel do enfermeiro na estratégia e saúde da família. Revista Científica da Faculdade de Educação e Meio Ambiente, 9(1), 348-372. 
Mascarello, K. C., Silva, M. F., Piske, M. T., Viana, K. C. G., Zandoneade, E., \& Amorim, M. H. C. (2012, jun.). Perfil Sociodemográfico e Clínico de Mulheres com Câncer do Colo do Útero Associado ao Estadiamento Inicial. Revista Brasileira de Cancerologia, 3(58), 417-426. Recuperado em $16 \quad$ abril, $2019, \quad$ de http://www1.inca.gov.br/rbc/n_58/v03/pdf/11_artigo_perfil_sociodemografico_clinico_mulhe res_cancer_colo_utero_associado_estadiamento_inicial.pdf

Melo, M. C. S. C., Vilela, F., Salimena, A. M. O., \& Souza, I. E. O. (2012). O Enfermeiro na Prevenção do Câncer do Colo do Útero: o Cotidiano da Atenção Primária. Revista Brasileira de Cancerologia, 3(58), 389-398. Recuperado em 23 abril, 2019, de http://www1.inca.gov.br/rbc/n_58/v03/pdf/08_artigo_enfermeiro_prevencao_cancer_colo_ut ero_cotidiano_atencao_primaria.pdf

Melo, W. A., Pelloso, S. M., Alvarenga, A., \& Carvalho, M. D. B. (2017). Fatores associados a alterações do exame citopatológico cérvico-uterino no Sul do Brasil. Revista Brasileira de Saude Maternal e Infantil, 17(4), 637-643. Recuperado em 17 abril, 2019, de http://www.scielo.br/scielo.php?script=sci_arttext\&pid=S1519-

$38292017000400637 \&$ Ing $=$ en\&nrm=iso

Mistura, C., Mistura, C., Silva, R. C. C., Melo, M. C. P., \& Sarmento, S. S. (2013, jul.). Papel do enfermeiro na prevenção do câncer de colo uterino na estratégia saúde da família. Revista Contexto \& Saúde, 11(20), 1161-1164. Recuperado em 23 abril, 2019 de https://www.revistas.unijui.edu.br/index.php/contextoesaude/article/view/1763

Moreira, L. S. (2016). Câncer de colo de útero: morbimortalidade e medidas para prevenção. Trabalho de Conclusão de Curso, Universidade Federal de Minas Gerais, Teófilo Otoni, MG, Brasil.

Navarro, C., Sibajev, A., Souza, C. I. de A., Araujo, D. S., Teles, D. A. F., Carvalho, S. G. L., Cavalcante, K. W. M., \& Rabelo, W. L. (2015). Cervical cancer screening coverage in a highincidence region. Revista de Saúde Pública, 49, 1-8, 2015.

Oliveira, M. V., Guimarães, M. D. C., FRANÇA, E. B. (2014, nov.). Fatores associados a não realização de Papanicolau em mulheres quilombolas. Ciência \& Saúde Coletiva, 19(11), 4535-4544. Recuperado em 17 abril, 2019, de https://www.scielosp.org/article/csc/2014.v19n11/4535-4544/

Oliveira, E. S., Silva, I. F., Araujo, A. J. de S., Santos, M. V. S., \& Queiroz, P. E. S. (2017, out.). A consulta de enfermagem frente à detecção precoce de lesões no colo do útero. Revista Enfermagem Contemporânea, 6(2), 186-198.

Paula, S. H. B., Volchoko, A., \& Figueiredo, R. (2017). Linha de cuidado de câncer de mama e de colo de útero: um estudo sobre referência e contrarreferência em cinco regiões de saúde de São Paulo, Brasil. BIS. Boletim do Instituto de Saúde, 17(2), 146-166. Recuperado em 17 abril, 2019, de https://www.researchgate.net/profile/Regina_Figueiredo2/publication/311921704_Linha_de _cuidado_de_cancer_de_mama_e_de_colo_de_utero_um_estudo_sobre_referencia_e_co ntrarreferencia_em_cinco_regioes_de_saude_de_Sao_Paulo_Brasil_The_Line_of_Care_fo r_breast_and_cervical_cancer_a_stu/links/58627e9208ae6eb871ab1977.pdf.

Resolução $n^{\circ}$ 385, de 2011. (2011). Altera o termo inicial de vigência da Resolução Cofen no 381, de 18 de julho de 2011, que normatiza a execução, pelo Enfermeiro, da coleta de material para colpocitologia oncótica pelo método de Papanicolau. Brasília, DF. Recuperado em 17 maio, 2019, de http://www.cofen.gov.br/resoluo-cofen-n-3852011_7934.html.

Ribeiro, L., Bastos, R. R., Vieira, M. T., Ribeiro, C. L., Teixeira, M. T. B., \& Leite, I. C. G. (2016). Rastreamento oportunístico versus perdas de oportunidade: não realização do exame de Papanicolaou entre mulheres que frequentaram o pré-natal. Caderno de Saúde Pública, 32(6). $\quad$ Recuperado em $17 \quad$ abril, 2019 de 
http://www.scielo.br/scielo.php?script=sci_arttext\&pid=S0102-

311 X2016000605003\&lng=pt\&nrm=iso

Santos, A. L. A., Moura, J. F. P., Santos, C. A. A. L., Figueria, J. N., \& Souza, A. I. (2012). Avaliação da Qualidade de Vida Relacionada à Saúde em Pacientes com Câncer do Colo do Útero em Tratamento Radioterápico. Revista Brasileira de Cancerologia, 58(3), 507-515.

Santos, M. O. (2018, jan.). Estimativa 2018: Incidência de Câncer no Brasil. Revista Brasileira de Cancerologia, 1(64), 119-120.

Silva, I. M. S. S., Monteiro, E. M., Silva, A. L., \& Bicalho, E. A. G. (2018, dez.). Incidência de câncer de colo uterino na cidade de patos de minas no período de 2013 á 2016: através de dados obtidos na SMS. Psicologia e Saúde em debate, 4(1), 75-75.

Silveira, C. F., Regino, P. A., Soares, M. B. O., Mendes, L. C., Elias, T. C., \& Silva, S. T. (2016). Qualidade de vida e toxicidade por radiação em pacientes com câncer ginecológico e mama. Escola Anna Nery - Revista de Enfermagem, 20(4), .1-20. Recuperado em 12 abril, 2019, de http://revistaenfermagem.eean.edu.br/detalhe_artigo.asp?id=1450\#B1

Soares, M. C., Mishima, S. M., Meincke, S. M. K., \& Simino, G. P. R. (2010, mar.). Câncer de colo uterino: caracterização das mulheres em um município do sul do Brasil. Escola Anna Nery - Revista de Enfermagem, 14(1), 90-96. Recuperado em 23 abril, 2019, de http://www.scielo.br/scielo.php?script=sci_arttext\&pid=S1414-

$81452010000100014 \& \operatorname{lng}=e n \& n r m=i s o$

Tavares, J. A., Moreira, A. D. (2017, dez.). Neoplasias do colo do útero. Revista Brasileira de Ciências da Vida, 5(4), 18. Recuperado em 15 abril, 2019, de http://jornal.faculdadecienciasdavida.com.br/index.php/RBCV/article/view/454

Teixeira, R. A., Valente, J. G., Franca, E. B. (2012, dez). Mortalidade por câncer de colo do útero no Estado de Minas Gerais, Brasil, 2004-2006: análise da magnitude e diferenciais regionais de óbitos corrigidos. Epidemiologia e Serviços de Saúde, 21(4), 549-559. Recuperado em 14 abril, 2019, de http://scielo.iec.gov.br/scielo.php?script=sci_arttext\&pid=S167949742012000400004\&lng=pt\&nrm=iso

Vilaça, M. N., Martins Junior, M. L., Scherrer, L. R., \& Rodrigues, A. N. (2012, dez.). Diferença nos padrões de tratamento e nas características epidemiológicas entre pacientes Idosas e Adultas portadores de Câncer do Colo do útero. Revista Brasileira de Cancerologia, 3(58), 497-505. Recuperado em 16 abril, 2019, de http://www1.inca.gov.br/rbc/n_58/v03/pdf/20b_artigo_diferencas_padroes_tratamento_cara cteristicas_epidemiologicas_pacientes_idosas_adultas_portadores_cancer_colo_utero.pdf 